\title{
Low grade transitional cell carcinoma of the urethra successfully treated with only intraurethral instillation of Mitomycin-C
}

\author{
Sharfuddeen A. Mashi, Sani A. Aji, Muzzammil Abdullahi, Bashir Yunusa, Sani U. Alhassan \\ Department of Surgery, Bayero University/Aminu Kano Teaching Hospital, Kano, Nigeria
}

\begin{abstract}
Urethral cancer is very rare disease, accounting for less than $0.5 \%$ of incidences of malignancies. Data on its management are scarce due to the rare nature of the cases. We present a 34-year-old man, who presented to our hospital with a month history of hematuria. He had no lower urinary tract symptoms and no significant risk factors for urothelial cancer. He was evaluated and found to have lesions in the posterior urethra on urethrocytoscopy, biopsy of which revealed a low-grade urothelial cancer. He was counselled and had 6 courses of intraurethral instillation of $40 \mathrm{mg}$ of
\end{abstract}

Correspondence: Sharfuddeen A. Mashi, Department of Surgery, Bayero University/Aminu Kano Teaching Hospital, No. 2 Zaria Road, Kano, Nigeria.

Tel.: +234.8037012706

E-mail: sharfumashi@gmail.com

Key words: Urethra, Urothelial cancer, Mitomycin-C.

Acknowledgements: the authors wish to thank Dr Yusuf Ibrahim of Histopathology Department of Aminu Kano Teaching Hospital for providing us with the photomicrographs of the patient's histology and Auwal Ismaila Abdullahi of the records department for retrieving the patient's folder and for going to the histopathology department to get the photomicrographs for us.

Contributions: SAM, BY and MA, contributed equally for the concept, design and writing of the manuscript; SAA, manuscript reviewing and most of the references; SUA, final critical appraisal and approval of the manuscript.

Conflict of interests: the authors declare no conflict of interest.

Funding: none.

Conference presentation: The abstract for this paper was presented at the 21st Annual General Meeting and Scientific Conference of the Nigerian Association of Urological Surgeons, Held at Ahmadu Bello University Teaching Hospital Zaria, Kaduna State, Nigeria. November 2015.

Received for publication: 16 April 2018.

Revision received: 27 June 2018.

Accepted for publication: 25 August 2018.

This work is licensed under a Creative Commons Attribution NonCommercial 4.0 License (CC BY-NC 4.0).

CCopyright S.A. Mashi et al., 2018

Licensee PAGEPress, Italy

Annals of African Medical Research 2018; 1:2

doi:10.4081/aamr.2018.2
Mitomycin-C diluited in $50 \mathrm{~mL}$ of saline Doctheld in the urethra with penile clamp for 30 minutes. The hematuria stopped after the second course, a repeat urethrocystoscopy 6 months after the completion of the chemotherapy, showed resolution of the lesion and repeat biopsy showed no evidence of malignancy. However, the patient developed short segment partial penile urethral stricture that was treated with dilatation. In conclusion, low-grade urothelial cancer of the urethra can be successfully cured with Intraurethral instillation of Mitomycin-C, without prior transurethral resection.

\section{Introduction}

Urethral cancer is very rare condition, accounting for less than $0.5 \%$ of incidences of malignancies. ${ }^{1}$ There is generally a scarce data on its management due to the rare nature of the disease. About $55-65 \%$ of the urothelial cancers are located in the posterior; and the bulbar parts of the urethra, while $30-35 \%$ occur in the remaining anterior urethra. ${ }^{2}$

Several treatment modalities for urethral cancer had been described. These include transurethral resection, ${ }^{3}$ radiotherapy, chemotherapy and combination therapy. ${ }^{4,5}$ They can all be effectively used in treating patients with this condition. Some authors have reported successful use of intraurethral instillation of Mitomycin C..$^{3,6}$ Mitomycin C is an antitumor antibiotic that is isolated from Streptomyces caespitosus. It is one of the most important chemotherapeutical agents that is used for urothelial cancers. 6,7 It acts by selectively inhibiting the synthesis of Deoxyribonucleic acid (DNA). High concentration of Mitomycin $\mathrm{C}$ suppresses both ribonucleic acid (RNA) and protein synthesis.

The use of intraurethral mitomycin $\mathrm{C}$ instillation, appears attractive due to relative ease of the procedure, however it is associated with some complications. ${ }^{3}$

Here we present a rare case of low-grade transitional cell carcinoma of the urethra that was successfully treated with intraurethral instillation of mitomycin $\mathrm{C}$, without prior transurethral resection or fulguration.

\section{Case Report}

BK is a 34-year-old man, who presented to our outpatient clinic with a month history of hematuria. He had no lower urinary tract symptoms, no previous history of hematuria and no significant risk factors for urothelial cancer.

Physical examination revealed a young man with normal findings in both general and systemic examinations, however urethrocystoscopy revealed lesions in the posterior urethra just proximal to the verumentanum, with normal looking bladder wall. Biopsy of the earlier noticed lesion revealed a low-grade urothelial carcinoma (Figure 1). Intravenous urography revealed no upper tract involvement .

He was counselled, prepared and had intraurethral instillation 
of $40 \mathrm{mg}$ of Mitomycin $\mathrm{C}$, diluted in $50 \mathrm{~mL}$ of saline, which was held up in the urethra for 30 minutes, using a penile clamp. A total of 6 courses were given at weekly intervals.

The hematuria stopped after the second course, but he developed irritative lower urinary tract symptoms which resolved a couple of weeks after the completion of the chemotherapy. Six months later when he came for a check urethrocystoscopy, a short segment partial penile urethral stricture was discovered. This was confirmed by retrograde urethrography and treated by dilatation.

The urethrocystoscopy done after dilatation of the stricture, revealed a mild hyperemia in the posterior urethra, otherwise healthy-looking posterior urethra. A repeat biopsy revealed no evidence of malignancy (Figures 2 and 3).

The patient was followed up for 4 years. He had no recurrence of hematuria and urethrocystoscopy revealed a healthy-looking posterior urethra.

\section{Discussion}

We report a successful curative treatment of urethral cancer using intraurethral instillation of mitomycin-C, in a 34-year-old man, without transurethral resection or fulguration of the tumor. Six courses were given to him at weekly intervals. He did very well, however he developed a partial short segment penile urethral stricture as a complication. Some authors have similarly described success with this method, ${ }^{3}$ but the intraurethral chemotherapy was given after initial transurethral resection of the tumor. Urethral stricture following intraurethral instillation of mitomycin $\mathrm{C}$ has also been described by Richard and colleagues. ${ }^{8}$

Some urologists had treated urethral cancer with transurethral resection alone, but reported recurrence following the procedure, however cure had been achieved with intraurethral instillation of mitomycin-C after the resection. ${ }^{3}$

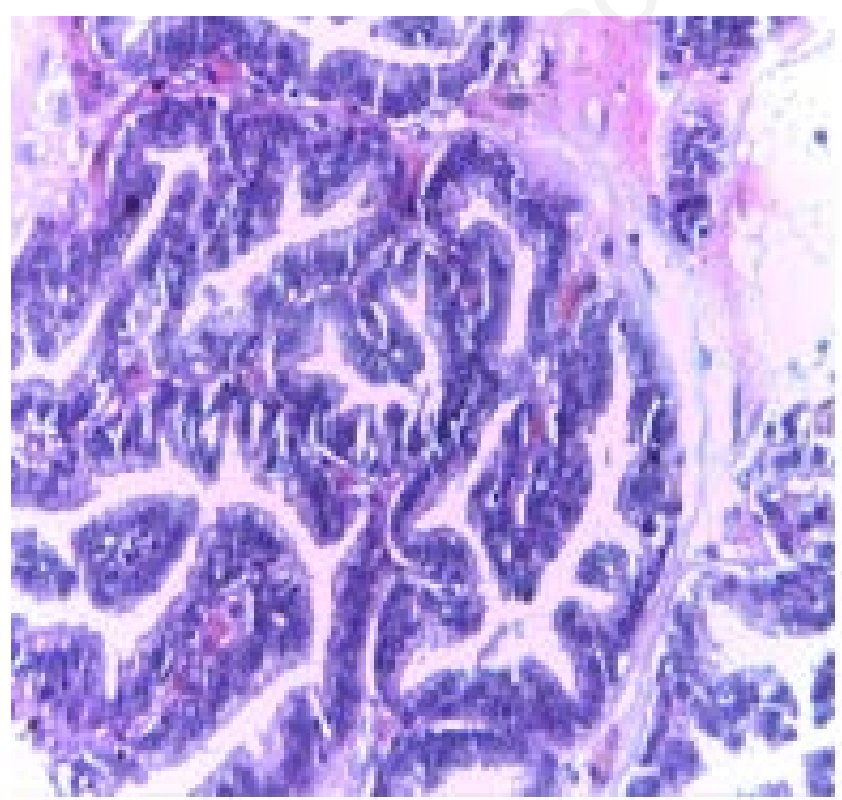

Figure 1. Section of the urethral biopsy before treatment showing papillae lined by multilayered urothelial cells with no cytologic atypia - low malignant potential.
Though very rare, other complications associated with the use of intraurethral instillation of mitomycin $\mathrm{C}$ includes: Glans necrosis (though this is seen after use of higher dose of $60 \mathrm{mg}$ ), necrosis of the corpus spongiosum and urethral sloughing. ${ }^{9}$

In our patient, we treated him successfully with intraurethral instillation of Mitomycin-C, without prior resection. He was followed up for four years, and he showed no evidence of the disease

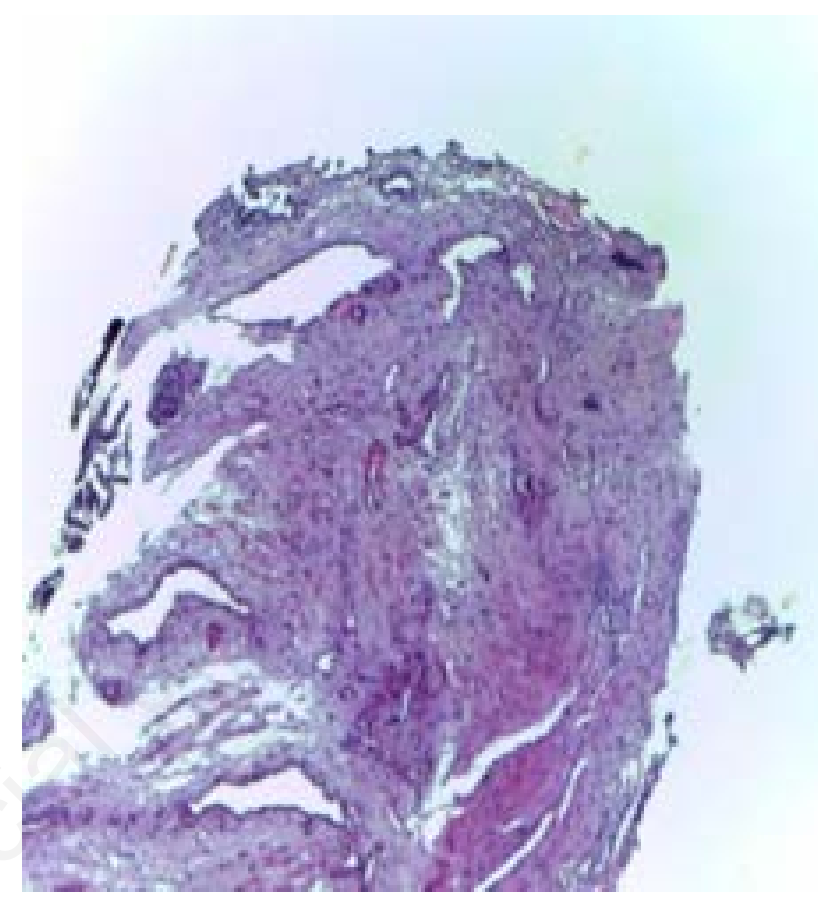

Figure 2. Section of urethral biopsy after treatment showing unremarkable fibromuscular tissue with no evidence of malignancy.

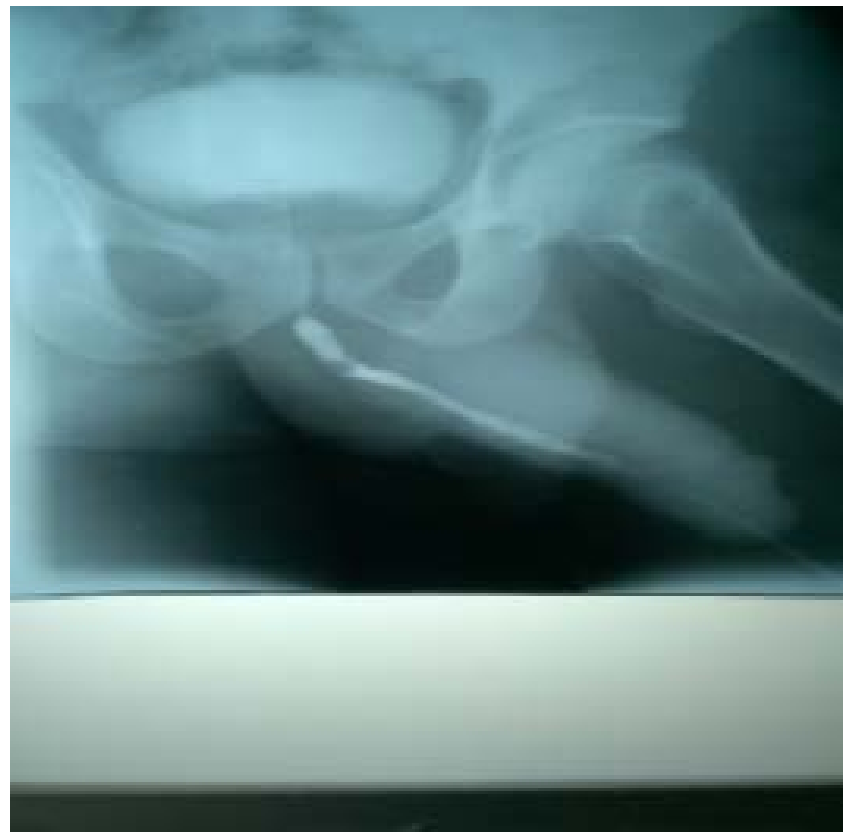

Figure 3. Retrograde urethrogram of the patient after treatment showing a short segment partial penile urethral stricture. 
recurrence.

We can therefore confidently recommend this form of treatment for selected patients with low grade transitional cell cancer of the urethra.

\section{Conclusions}

Low grade Urothelial cancer of the urethra can be successfully cured with Intraurethral instillation of mitomycin C, without prior transurethral resection. Although it is associated with some complications, they are generally rare from the reported literature.

\section{References}

1. Donat S, Cozzi P, Herr H. W. Surgery of penile and urethral carcinoma. Campbell's Urology. 2002. pp. 2991-2993.

2. Verheyden B, Debruyne P. Urethral tumors. In: Krane RJ, Siroky MB, Fitzpatrick JM, Eds. Clinical Urology. Philadelphia: Lippincott Williams \& Wilkins; 1994. pp. 1010-
1012.

3. Melonakos EJ, Santucci RA. Treatment of low-grade bulbar transitional cell carcinoma with urethral instillation of mitomycin C. Adv Urol 2008:173694.

4. Eastham JA, Huffman JL. Technique of mitomycin C instillation in the treatment of upper urinary tract urothelial tumors. J Urol 1993;150:324 $\square$.

5. Keeley FX Jr, Bagley DH. Adjuvant mitomycin C following endoscopic treatment of upper tract transitional cell carcinoma. J Urol 1997;158:2074 $\square 7$.

6. Dalbagni G, Zhang Z. F, Lacombe L, Herr H. W. Male urethral carcinoma: analysis of treatment outcome. Urology 1999;53:1126-32.

7. Gheiler EL, Tefilli MV, Tiguert R, et al. Management of primary urethral cancer. Urology 1998;52:487-93.

8. Stanford RFJ, Thomas SA. Focal urethral stricturing following intraurethral Mitomycin-C gel and the use of a penile clamp. Case Rep Urol 2012;864741.

9. Neulander EZ, Lismer L, Kaneti J. Necrosis of the glans penis: a rare complication of intravesical therapy with mitomycin $\mathrm{C}$. J Urol 2000;164:1306. 